Article

\title{
A Comprehensive Characterization of a 10 at. $\%$ Yb:YSAG Laser Ceramic Sample
}

\author{
Angela Pirri ${ }^{1}$, Guido Toci ${ }^{2, *}$, Jiang $\mathrm{Li}^{3}$, Yagang Feng ${ }^{3}$, Tengfei Xie ${ }^{3}$, Zhaoxiang Yang ${ }^{3}$, \\ Barbara Patrizi ${ }^{4}$ and Matteo Vannini ${ }^{2}$ \\ 1 Istituto di Fisica Applicata "Carrara", IFAC, Consiglio Nazionale delle Ricerche, CNR, \\ Via Madonna del Piano 10C, 50019 Sesto Fiorentino (Fi), Italy; a.pirri@ifac.cnr.it \\ 2 Istituto Nazionale di Ottica, INO, Consiglio Nazionale delle Ricerche, CNR, Via Madonna del Piano 10C, \\ 50019 Sesto Fiorentino (Fi), Italy; matteo.vannini@ino.cnr.it \\ 3 Key Laboratory of Transparent and Opto-functional Inorganic Materials, Shanghai Institute of Ceramics, \\ Chinese Academy of Sciences, Shanghai 201899, China; lijiang@mail.sic.ac.cn (J.L.); \\ fengyagang@student.sic.ac.cn (Y.F.); xietengfei120800@163.com (T.X.); yangzx@mail.sic.ac.cn (Z.Y.) \\ 4 Istituto Nazionale di Ottica, INO, Consiglio Nazionale delle Ricerche, CNR, Via G. Moruzzi 1, 56124 Pisa, \\ Italy; barbara.patrizi@ino.cnr.it \\ * Correspondence: guido.toci@ino.cnr.it; Tel.: +39-(0)55-522-5315
}

Received: 5 April 2018; Accepted: 11 May 2018; Published: 18 May 2018

Abstract: We report a comprehensive characterization of a 10 at. $\% \mathrm{Yb}^{3+}$-doped YSAG $\left(\mathrm{Yb}: \mathrm{Y}_{3} \mathrm{Sc}_{\mathrm{x}} \mathrm{Al}_{(5-\mathrm{x})} \mathrm{O}_{12}, \mathrm{x}=1.5\right)$ ceramic, including microstructural, spectroscopic and laser properties. Moreover, we illustrate and discuss the fabrication technique. $\mathrm{Yb}^{3+}$ in YSAG features a broader absorption and emission band than in traditional YAG, which is advantageous for laser applications (i.e., tunable laser sources, ultrafast pulse generation). Pumping in a quasi continuous wave regime at $936 \mathrm{~nm}$, the ceramic has shown good laser performance as the maximum output power was $6.3 \mathrm{~W}$ with a corresponding slope efficiency $\left(\eta_{\mathrm{s}}\right)$ of $67.8 \%$. In continuous wave regime instead, the maximum output power was $5 \mathrm{~W}$ with $\eta_{\mathrm{s}}=52.7 \%$. The laser emission wavelengths in free running were $\lambda_{\mathrm{L}}=1051 \mathrm{~nm}$ and $\lambda_{\mathrm{L}}=1031 \mathrm{~nm}$, depending on the output coupler transmission. Finally, by a tunable cavity we obtained laser emission spanning from 991.5 to $1073 \mathrm{~nm}$, i.e., $81.5 \mathrm{~nm}$, which is the broadest tuning range ever reported for this material, to the best of our knowledge.

Keywords: transparent laser ceramic; ytterbium-doped laser ceramics; diode-pumped solid-state laser; tunable laser cavity

\section{Introduction}

In the last years, several polycrystalline disordered materials, such as Yb:LuYAG [1-3] or Nd:YSAG [4], were fabricated and characterized. These gain materials show a broader emission bandwidth respect to other pure hosts, like $\mathrm{YAG}[5], \mathrm{Sc}_{2} \mathrm{O}_{3}$ and $\mathrm{Y}_{2} \mathrm{O}_{3}$; moreover, their emission peaks can be tuned toward longer wavelengths [6]. As a matter of fact, these laser materials are suitable for developing tunable laser systems for use in remote sensing systems as well as to generate short pulses below $100 \mathrm{fs}[7,8]$. At the same time, starting from undoped matrices with high thermal conductivity, they can preserve good thermal properties, making them suitable for high-average power lasers.

Concerning the $\mathrm{Y}_{3} \mathrm{Sc}_{\mathrm{x}} \mathrm{Al}_{(5-\mathrm{x})} \mathrm{O}_{12}$ matrix (crystals $[9,10]$ or ceramics), it is obtained by a partial substitution of $\mathrm{Al}^{3+}$ ions with $\mathrm{Sc}^{3+}$ ions in the $\mathrm{Y}_{3} \mathrm{Al}_{5} \mathrm{O}_{12}$ matrix. $\mathrm{Sc}^{3+}$ ion, owing a larger atomic radius respect to $\mathrm{Al}^{3+}$ distorts the crystal structure with a consequent increase of the lattice constant [6].

The modification in the crystal field results in a larger splitting of the sublevels of the upper $\left({ }^{2} \mathrm{~F}_{5 / 2}\right)$ and of the lower $\left({ }^{2} \mathrm{~F}_{7 / 2}\right)$ manifolds of $\mathrm{Yb}^{3+}[11]$, whereas the overall separation between the manifold 
barycenters (due to the spin-orbit splitting) remains constant [11], as it is with good approximation host-independent $[12,13]$. All the host-induced structural effects described above determine a red shift of the main $\mathrm{Yb}^{3+}$ emission peaks.

The presence of $\mathrm{Sc}^{3+}$ ions, in addition, produces an inhomogeneous broadening of the emission bandwidth. However, the balance between $\mathrm{Sc}^{3+}$ and $\mathrm{Al}^{3+}$ should be chosen carefully as it influences the lifetime of the laser transition and, as a consequence, the laser threshold.

The first $\mathrm{Y}_{3} \mathrm{Sc}_{\mathrm{x}} \mathrm{Al}_{(5-\mathrm{x})} \mathrm{O}_{12}$ ceramic doped with $\mathrm{Nd}^{3+}$ was fabricated by Sato et al. in 2003 [14] . In 2004, Saikawa et al. [11] demonstrated the laser action of 15 at. $\% \mathrm{Yb}^{3+}$-doped $\mathrm{Y}_{3} \mathrm{ScAl}_{4} \mathrm{O}_{12}$ ceramic obtained by a reactive sintering process. In particular, in Continuous Wave (CW) the laser delivered a maximum output power of $600 \mathrm{~mW}$ with a slope efficiency $\eta_{\mathrm{s}}=72 \%$ at a lasing wavelength of $\lambda_{\mathrm{L}}=1032 \mathrm{~nm}$ and pumping wavelength of $\lambda_{\mathrm{P}}=970 \mathrm{~nm}$. Pulses of $280 \mathrm{fs}$ at $\lambda_{\mathrm{L}}=1035.8 \mathrm{~nm}$ were obtained by a passively mode-locked cavity based on 5 at. $\% \mathrm{Yb}: \mathrm{Y}_{3}\left(\mathrm{Sc}_{0.5} \mathrm{Al}_{0.5}\right)_{5} \mathrm{O}_{12}$. Moreover, it was demonstrated a tuning range of $52 \mathrm{~nm}$ while the slope efficiency was $\eta_{\mathrm{s}}=72 \%$ [7]. In a recent paper, $\mathrm{Ma}$ and co-workers [15] have tested a $\mathrm{Yb}: \mathrm{Y}_{3} \mathrm{ScAl}_{4} \mathrm{O}_{12}$ ceramic obtaining mode-locked laser pulses with a duration of $96 \mathrm{fs}$ at $1052 \mathrm{~nm}$, and a repetition rate of $102 \mathrm{MHz}$; they have obtained a maximum average output power that was $51 \mathrm{~mW}$.

This paper is devoted to exploring the overall potentiality of a laser prototype based on a 10 at.\% $\mathrm{Yb}: \mathrm{Y}_{3} \mathrm{Sc}_{1.5} \mathrm{Al}_{3.5} \mathrm{O}_{12}$ ceramic. The sample has been fabricated by solid-state reaction combined with vacuum sintering and its microstructure has been characterized through Field Emission Scanning Electron Microscopy (FESEM) and X-ray Diffraction (XRD). We present a spectroscopic characterization of the ceramic, in particular, the absorption and the emission cross section spectra and the upper laser level lifetime. Laser tests were carried out in Quasi-Continuous Wave (QCW) and in CW operation modes at room temperature. The implementation of a tunable cavity has allowed measuring a tuning curve as wide as $81.5 \mathrm{~nm}$, which is comparable with data obtained with $\mathrm{Yb}^{3+}$ in fluoride hosts [16-18]. To the best of our knowledge, this is the broadest tuning range reported in literature for this material.

\section{Ceramic Fabrication Technique}

Commercial powders of $\mathrm{Y}_{2} \mathrm{O}_{3}$ (99.99\%, Yuelong, Shanghai, China), $\mathrm{Sc}_{2} \mathrm{O}_{3}(99.99 \%$, Jingyun, Shanghai, China), $\alpha-\mathrm{Al}_{2} \mathrm{O}_{3}$ (99.99\%, Fenghe, Shanghai, China), and $\mathrm{Yb}_{2} \mathrm{O}_{3}$ (99.99\%, Zhongkai, Shandong, China) were used as staring materials to fabricate 10 at. $\%$ Yb: $\mathrm{Y}_{3} \mathrm{Sc}_{1.5} \mathrm{Al}_{3.5} \mathrm{O}_{12}$ (i.e., $\mathrm{Yb}_{0.3} \mathrm{Y}_{2.7} \mathrm{Sc}_{1.5} \mathrm{Al}_{3.5} \mathrm{O}_{12}$ ) ceramics. MgO powder (99.998\%, Alfa Aesar, Tianjin, China) and tetraethoxysilane (TEOS, >99.999\%, Alfa Aesar, Tianjin, China) were used as sintering aids. The powders were mixed in ethanol and ball-milled with high-purity corundum balls for $12 \mathrm{~h}$. After the ball milling, the slurry was dried at $70{ }^{\circ} \mathrm{C}$ for $2 \mathrm{~h}$ in an oven and then sieved through 200-mesh screen.

The powder mixtures were calcined at $600{ }^{\circ} \mathrm{C}$ for $4 \mathrm{~h}$ to remove the organic components. The calcined powders were uniaxially pressed into $18 \mathrm{~mm}$ diameter pellets at low pressure (46 MPa) and then the green bodies obtained were isostatically pressed at $250 \mathrm{MPa}$ at room temperature. The pellets were sintered at $1820^{\circ} \mathrm{C}$ for $30 \mathrm{~h}$ in a tungsten mesh-heated vacuum furnace and then annealed in air at $1450{ }^{\circ} \mathrm{C}$ for $20 \mathrm{~h}$ to remove the oxygen vacancies. Finally, the ceramics were mirror-polished on both surfaces and reduced to $2.0 \mathrm{~mm}$ of thickness for optical measurements. The polished specimens were thermally etched at $1450{ }^{\circ} \mathrm{C}$ for $3 \mathrm{~h}$ to expose the grain boundaries for the microstructural analysis.

Figure 1a shows the FESEM micrograph of the thermally etched surface of a 10 at.\% $\mathrm{Yb}: \mathrm{Y}_{3} \mathrm{Sc}_{1.5} \mathrm{Al}_{3.5} \mathrm{O}_{12}$ transparent ceramics sintered at $1820{ }^{\circ} \mathrm{C}$ for $30 \mathrm{~h}$. The grain composing the sample have an average size of $44 \mu \mathrm{m}$, determined by the linear intercept method (more than 200 grains were counted); the grain boundaries are very clean; at the grain boundaries and in the inner grains the presence of pores is quite negligible. 

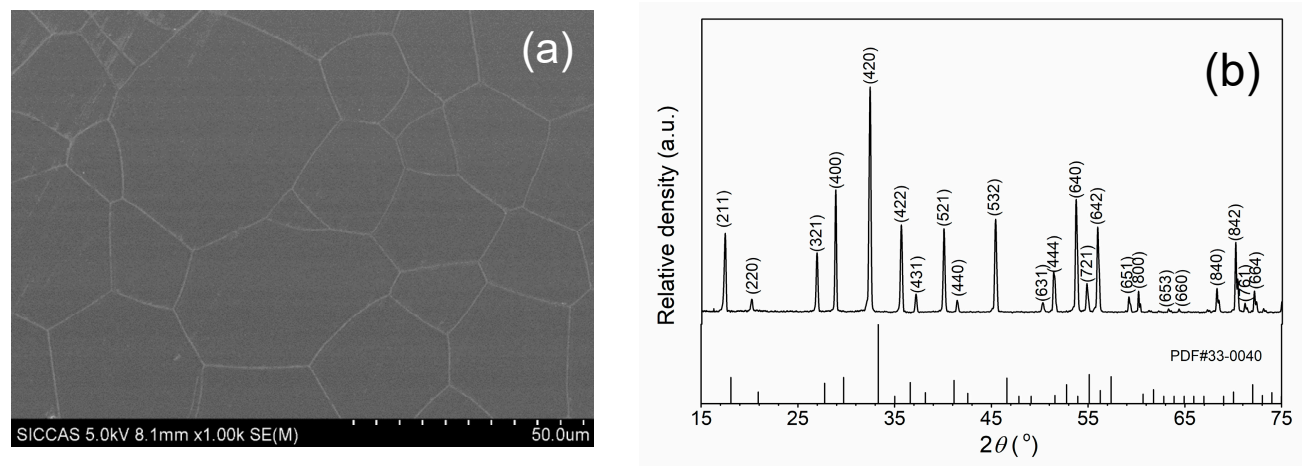

Figure 1. (a) Field Emission Scanning Electron Microscopy FESEM micrograph of the thermally etched surface of a 10 at.\% $\mathrm{Yb}: \mathrm{Y}_{3} \mathrm{Sc}_{1.5} \mathrm{Al}_{3.5} \mathrm{O}_{12}$ transparent ceramics sintered at $1820{ }^{\circ} \mathrm{C}$ for $30 \mathrm{~h}$; (b) XRD pattern of the sample.

Figure $1 \mathrm{~b}$ shows the XRD pattern of the Yb:YSAG sample. The ceramics crystal structure shows the expected cubic garnet phase with a lattice parameter of $1.2225 \mathrm{~nm}$, which is about $2 \%$ larger than that of the lattice constant reported for $10 \mathrm{at} . \% \mathrm{Yb}^{3+}$ doped YAG that is $1.200058 \mathrm{~nm}$ [19].

\section{Spectroscopic and Optical Characterization}

The spectroscopic characterization was aimed mainly to determine the absorption and the emission cross section spectra of the $\mathrm{Yb}^{3+}$ in the sample, and to determine the upper laser level lifetime.

The transmission spectrum of the ceramic sample was measured with a Perkin Elmer Lambda 1050 spectrophotometer, with a spectral resolution of $1 \mathrm{~nm}$ (Figure 2a).

The transmission spectrum, see Figure $2 \mathrm{a}$, clearly shows the absorption bands due to the $\mathrm{Yb}^{3+2} \mathrm{~F}_{5 / 2}-{ }^{2} \mathrm{~F}_{7 / 2}$ transition in the range 900-1020 nm. No other absorption features can be seen between 300 and $900 \mathrm{~nm}$.

Regarding the theoretical transmission, to our knowledge no refractive index data are available in literature for this specific composition; Allik et al. [10] reported a value of the refractive index of 1.873 at $632.8 \mathrm{~nm}$ for $\mathrm{Nd}$-doped $\mathrm{Y}_{3} \mathrm{Sc}_{2} \mathrm{Al}_{3} \mathrm{O}_{12}$, from which a theoretical transmission value of $82.39 \%$ (due to the Fresnel reflections) can be calculated. This is very similar to the measured value of $81.65 \%$ obtained at the same wavelength. The scattering coefficient at $632.8 \mathrm{~nm}$ is then about $0.05 \mathrm{~cm}^{-1}$.
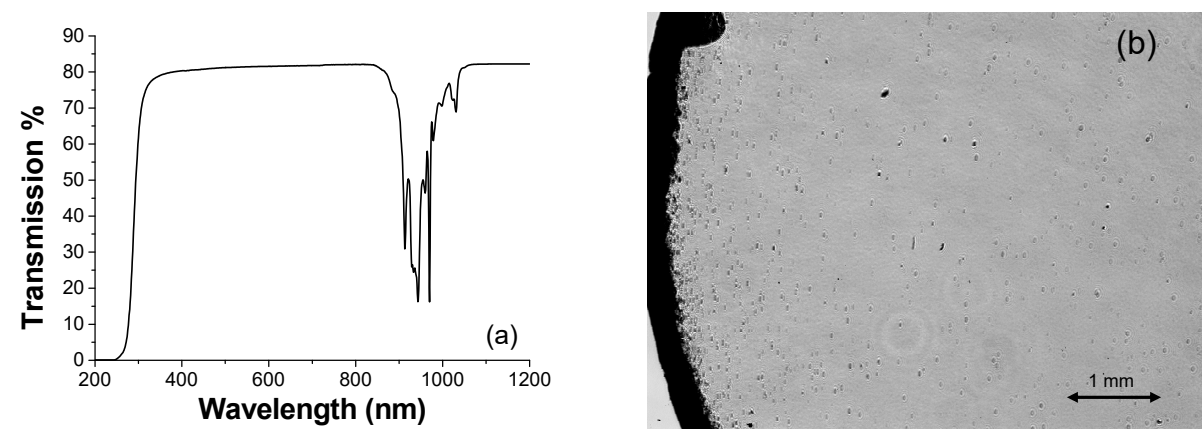

Figure 2. (a) Transmission spectrum of the $1.85 \mathrm{~mm}$-length ceramic sample under test; (b) Microscopic transmission image of the sample. The size of the displayed area is $\sim 5.9 \times 4.4 \mathrm{~mm}$. The dark band on the left side is the edge of the sample.

Figure $2 \mathrm{~b}$ reports the microscopic optical image (in transmission) of the sample, showing the distribution of the residual pores that appear as dark spots in the image. The optical uniformity of the sample is quite good, and the residual pores are mainly distributed near to the edge of the sample. Their presence does not influence significantly the transmission of the sample (see Figure 2a). 
The cations sites density of the $\mathrm{Y}_{3} \mathrm{Sc}_{1.5} \mathrm{Al}_{3.5} \mathrm{O}_{12}$, calculated from the lattice constant value of $1.2225 \mathrm{~nm}$ (determined by X-ray diffraction measurements), is $1.314 \times 10^{22}$ ions $/ \mathrm{cm}^{3}$. From the transmission spectrum of Figure 2a it was then possible to calculate the absorption cross section spectrum, shown in Figure 3a.
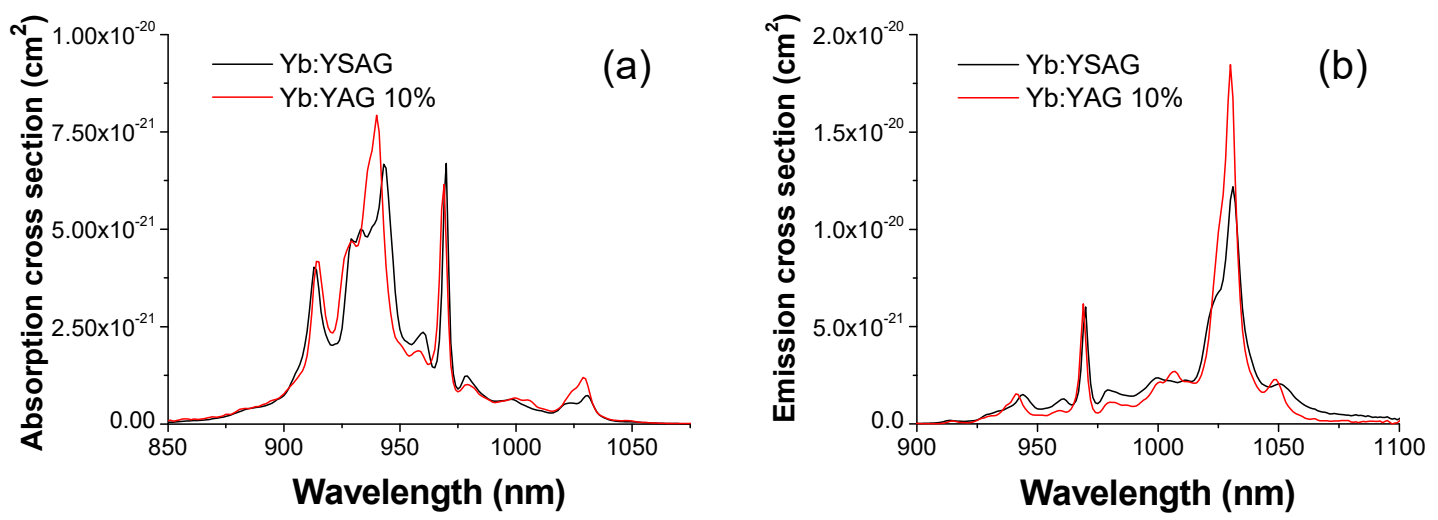

Figure 3. (a) Absorption cross section spectrum $\left(\sigma_{a b s}\right)$ for the 10 at. $\%$ Yb: $\mathrm{Y}_{3} \mathrm{Sc}_{1.5} \mathrm{Al}_{3.5} \mathrm{O}_{12}(\mathrm{Yb}: \mathrm{YSAG})$ sample, obtained from the transmission spectrum reported in Figure 2a. For comparison it is also shown the absorption cross section spectrum of a 10 at.\%-doped Yb:YAG ceramics produced with the same method; (b) Emission cross section spectra $\left(\sigma_{e m}\right)$ for Yb:YSAG and Yb:YAG calculated from the absorption cross section spectra using the reciprocity method (see text).

The absorption cross section of $\mathrm{Yb}^{3+}$ features a broad peak at about $943 \mathrm{~nm}$, whereas the zero-phonon line peak is located at $969.7 \mathrm{~nm}$. By comparing it with the absorption cross section spectrum of $\mathrm{Yb}$ :YAG (also shown in Figure 3a), it appears that both the main absorption peak (peaked at $939.4 \mathrm{~nm}$ in YAG) and the zero line peak (at $968.93 \mathrm{~nm}$ in YAG) are slightly shifted toward longer wavelengths. Moreover, at about $1030 \mathrm{~nm}$ (one of the main lasing wavelengths) the ground level absorption cross section of $\mathrm{Yb}^{3+}$ in YSAG is lower than in YAG.

The emission cross section spectrum $\sigma_{e m}(\lambda)$ (Figure $3 b$ ) was calculated from the absorption cross section spectrum $\sigma_{a b}(\lambda)$ by means of the reciprocity (McCumber) formula [20]:

$$
\sigma_{e m}(\lambda)=\sigma_{a b}(\lambda)\left[Z_{l} / Z_{u}\right] \exp \left[\left(E_{Z L}-h c / \lambda\right) / k_{B} T\right]
$$

where $E_{Z L}$ is the energy of the zero-phonon line transition, $h$ is the Planck's constant, $c$ is the speed of light, $k_{B}$ is the Boltzmann constant, $T$ is the temperature, $Z_{l}$ and $Z_{u}$ are the partition functions of the lower and upper level, respectively. For the evaluation of $Z_{l} / Z_{u}$ we used the values of the energy levels for $\mathrm{Yb}$ in YSAG and YAG reported by Saikawa et al. [11]. Even though these values are valid for the host composition $\mathrm{Y}_{3} \mathrm{Sc}_{2} \mathrm{Al}_{3} \mathrm{O}_{12}$, the resulting value of $Z_{l} / Z_{u}$ at room temperature for ${ }_{3} \mathrm{Sc}_{2} \mathrm{Al}_{3} \mathrm{O}_{12}$ (0.8835) is very close to that of YAG (0.8817). We assumed then that in Equation (1) the same value can be used as a good approximation for the value of $Z_{l} / Z_{u}$ in $\mathrm{Y}_{3} \mathrm{Sc}_{1.5} \mathrm{Al}_{3.5} \mathrm{O}_{12}$.

These measurements confirm the trend already observed by Saikawa et al. [11]: the main emission cross section peak in $\mathrm{Yb}: \mathrm{Y}_{3} \mathrm{Sc}_{1.5} \mathrm{Al}_{3.5} \mathrm{O}_{12}$, located at about $1031 \mathrm{~nm}$, has a lower peak value (about $1.2 \times 10^{-21} \mathrm{~cm}^{2}$ ) than the corresponding peak in Yb:YAG (about $1.8 \times 10^{-21} \mathrm{~cm}^{2}$ at $1030 \mathrm{~nm}$ ), but it is significantly broader than in YAG (13 nm vs. $8.5 \mathrm{~nm}$ FWHM). Furthermore, the emission spectrum of $\mathrm{Yb}: \mathrm{Y}_{3} \mathrm{Sc}_{1.5} \mathrm{Al}_{3.5} \mathrm{O}_{12}$ shows a relatively high tail extending up to $1075 \mathrm{~nm}$ and above, whereas in the same spectral region the emission cross section of Yb:YAG decreases quite rapidly. It must be noticed

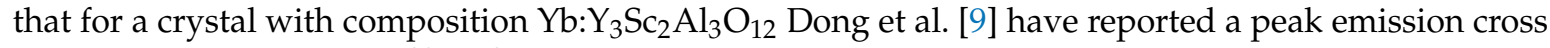
section of about $1.9 \times 10^{-20} \mathrm{~cm}^{2}$ at $1030.7 \mathrm{~nm}$ (that is larger than both our value and that reported by Saikawa et al. [11]) and a slightly larger peak bandwidth ( 13.3 nm FWHM). 
The lifetime of the upper level was measured by means of the so-called pinhole method to compensate for radiation trapping effects [21-23] and using a pulsed ns Ti:Sapphire laser as excitation source. We obtained a lifetime value of $966 \pm 6 \mu \mathrm{sec}$. This is comparable with the value commonly accepted for Yb:YAG ( $\sim 950 \mu \mathrm{sec}$, [23]), but shorter than the value ( 1.1 msec) reported for both the ceramics with composition $\mathrm{Yb}: \mathrm{Y}_{3} \mathrm{ScAl}_{4} \mathrm{O}_{12}$ (Saikawa et al. [11]) and for the crystal with composition $\mathrm{Yb}: \mathrm{Y}_{3} \mathrm{Sc}_{2} \mathrm{Al}_{3} \mathrm{O}_{12}$ (Dong et al. [9]). The shortening of the lifetime could be related to some non-radiative decay processes affecting the upper laser level of $\mathrm{Yb}^{3+}$, due to defects in the crystal lattice. On the other hand, it must be noticed that in Ref. [11] the upper level lifetime was not measured directly, but determined as a fitting parameter to match the emission spectrum obtained from the reciprocity formula and from the Füchtbauer-Ladenburg method applied to the fluorescence spectrum. Ref. [9], instead, actually reports the measured fluorescence lifetime, which could be affected by radiation trapping effects, resulting in a larger value than the actual upper level lifetime.

\section{Laser Results and Analysis}

The laser behavior of the ceramic was tested by using the V-shape cavity reported in Figure 4 . The uncoated ceramic, of $1.85 \mathrm{~mm}$ length and doping concentration of $10 \mathrm{at} . \% \mathrm{Yb}^{3+}$, was welded by a sheet of indium on a copper heat-sink and cooled with water at $17^{\circ} \mathrm{C}$. The input and output facets of the sample were polished for optical measurements.

The ceramic was pumped by a fiber-coupled laser-diode which emits at $936 \mathrm{~nm}$ with a Gaussian pump intensity distribution in the region of the focal plane (i.e., waist radius around $95 \mu \mathrm{m}$ at $1 / \mathrm{e}^{2}$, measured with a Charge-Coupled Device (CCD) camera). With this cavity we performed two sets of measurements. In the first, the ceramic was pumped in QCW regime, at $10 \mathrm{~Hz}$ of repetition rate with a duty factor of $\mathrm{DF}=20 \%$, in order to limit the thermal load into the ceramic. In the second set of measurements, the ceramic was pumped in $\mathrm{CW}$ regime. With both schemes the maximum incident pump power was $19.2 \mathrm{~W}$.

Figure 5 reports the QCW laser output power as a function of the absorbed pump power, $\mathrm{P}_{\mathrm{abs}}$, measured by using different output coupler mirrors; their transmission ranged from $T=2.2 \%$ to $T=37.7 \%$. The highest slope efficiency was achieved with $T=18.8 \%$, i.e., $\eta_{\mathrm{s}}=67.8 \%$, while the laser maximum output power of $6.3 \mathrm{~W}$ at $\lambda_{\mathrm{L}} \sim 1031 \mathrm{~nm}$ was obtained with both the output coupler mirrors with $T=18.8 \%$ and with $T=37.7 \%$. The longest wavelength in free running lasing, i.e., $\lambda_{\mathrm{L}}=1051 \mathrm{~nm}$, is measured with $T=2.2 \%$ (which has also given the lowest laser threshold, i.e., $\mathrm{P}_{\text {th }}=0.74 \mathrm{~W}$ ).

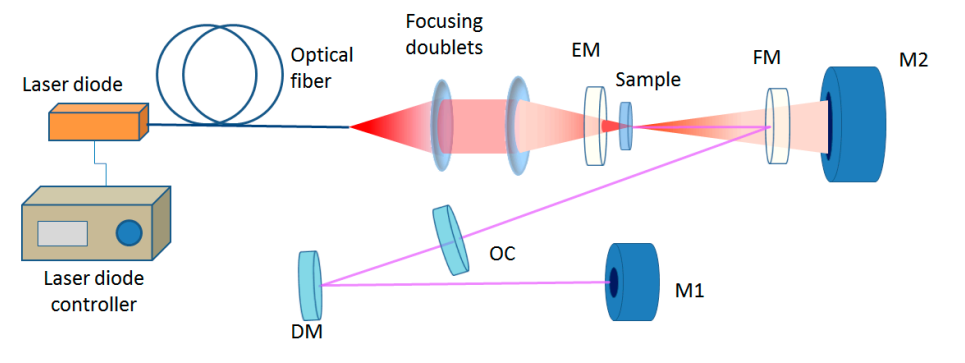

$$
\begin{aligned}
& \mathrm{Yb}: \mathrm{Y}_{3}\left(\mathrm{Sc}_{0.3} \mathrm{Al}_{0.7}\right)_{5} \mathrm{O}_{12} \\
& \mathrm{Yb}: \mathrm{Y}_{3}\left(\mathrm{~S}=0.3 \mathrm{Ai}_{0.7}\right)_{5} \mathrm{O}_{12} \\
& \mathrm{Yb}: \mathrm{Y}_{3}\left(\mathrm{~S}_{\mathrm{C}_{0} 3} \mathrm{~A} \mathrm{~A} .7\right)_{5} \mathrm{O}_{12} \\
& \mathrm{Yb}: \mathrm{Y}_{3}\left(\mathrm{Sc}_{0.3} \mathrm{Al}_{0.7}\right)_{5} \mathrm{O}_{12}
\end{aligned}
$$

Figure 4. V-shaped laser cavity with a folding half angle of $10^{\circ}$. C: Ceramic sample; EM: End-Mirror; FM: Folding-Mirror (ROC 100 mm); OC: Flat Output Coupler mirror; M1 and M2: Power Meters, DM: Dichroic Mirror. The distance between FM and EM is $56 \mathrm{~mm}$, and the distance between FM and OC is $220 \mathrm{~mm}$. the ceramic was pumped at $936 \mathrm{~nm}$. The inset on the right shows the sample used in the experiment $(\varnothing 13.5 \mathrm{~mm})$.

Concerning the red shift of the emission wavelength, observed using an Output Coupler (OC) with a lower transmittance, this effect can be addressed to the quasi three-level system behavior of the $\mathrm{Yb}^{3+}$. As a matter of fact, using OCs with higher transmission, the cavity losses increases, and in turn, the fraction of the excited population needed to reach the lasing threshold increases as well 
determining a shift of the peak of the effective gain spectrum toward shorter wavelengths (gain-tuning effect [8]).

From the values of the slope efficiency obtained with output couplers with different transmission, it was possible to calculate the overall internal losses of the cavity by means of the Caird formula [24]. We obtained a single pass loss of $1.7 \%$, which is slightly higher than the estimated internal transmission losses of the sample $(\sim 0.7 \%)$ and is probably also affected by the residual losses due to the Fresnel reflection at the interfaces.

Remarkable results are confirmed in CW pumping. Two different measurements were performed using mirrors with $T=11.7 \%$ and $T=18.8 \%$ as output couplers. Very similar results in terms of output power and slope efficiency were found with the two output couplers as reported in Figure 6a. In particular, the laser delivered $\mathrm{P}_{\text {out }}=5 \mathrm{~W}$ with both output couplers while the slope efficiency were $\eta_{\mathrm{s}}=52.2 \%$ and $\eta_{\mathrm{s}}=52.7 \%$, respectively; the laser threshold and the emission wavelength remained instead unchanged. It must be noticed that in CW the pump absorption is slightly increased as a consequence of the emission wavelength red shift of the pump laser. From these data it appears that the thermal load determines only a modest decrease of the laser performance, in particular, the maximum output power decreases from $6 \mathrm{~W}\left(\eta_{\mathrm{s}}=65.1 \%\right)$ to $5 \mathrm{~W}\left(\eta_{\mathrm{s}}=52.7 \%\right)$ switching from QCW to $\mathrm{CW}$ at the same pump power values (Figure $5 b$ ). These results demonstrate the high thermal quality of this material. Finally, we note that the laser threshold and the emission wavelength remained unchanged, i.e., $\mathrm{P}_{\text {th }} \sim 1 \mathrm{~W}, \lambda_{\mathrm{L}} \sim 1031 \mathrm{~nm}$.
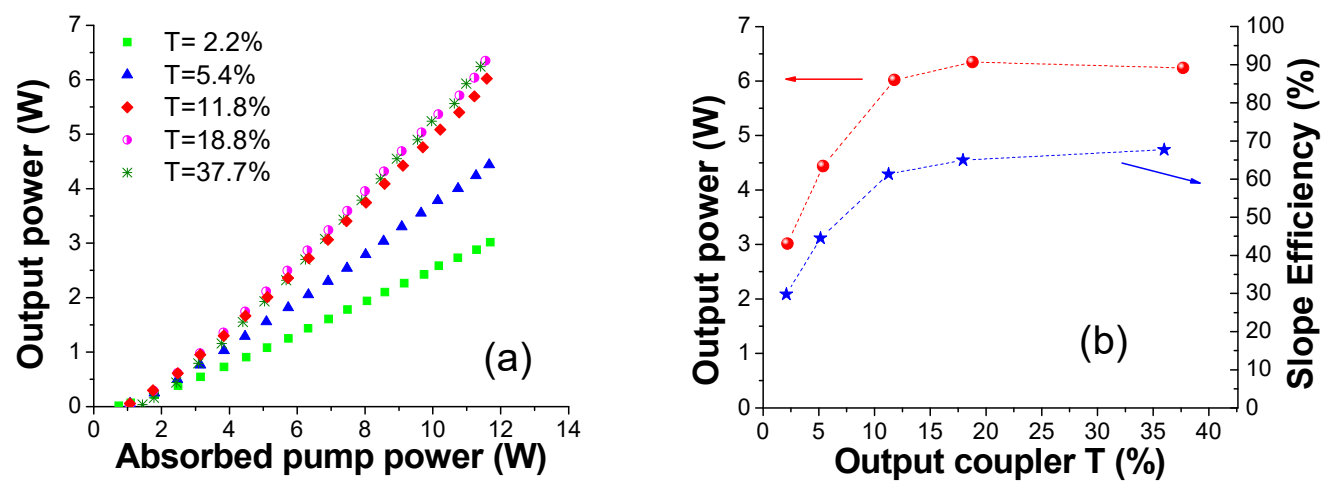

Figure 5. QCW laser output power versus the absorbed pump power (a). Maximum output power and the corresponding slope efficiency as a function of the OCs transmission, T (\%) (b). The unsaturated absorptions of the ceramic are $68.2 \%(\mathrm{QCW})$ and $73.8 \%(\mathrm{CW})$, respectively.
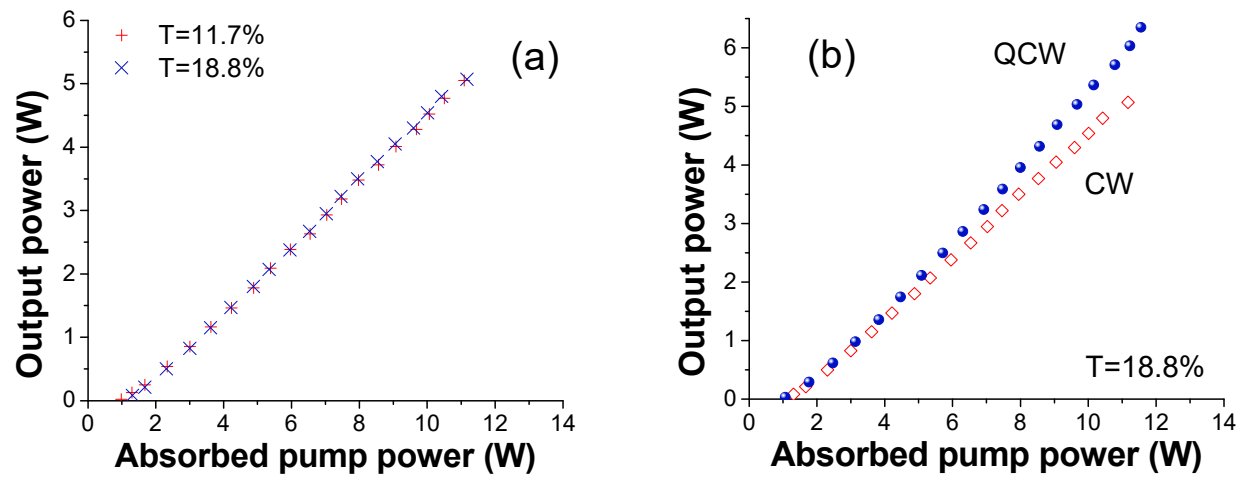

Figure 6. $\mathrm{CW}$ laser output power ( $\left.\mathrm{P}_{\text {out }}\right)$ versus the absorbed pump power $\left(\mathrm{P}_{\mathrm{abs}}\right)(\mathrm{a})$ with two OCs, i.e., $\mathrm{T}=11.7 \%$ and $\mathrm{T}=18.8 \%$; In $(\mathbf{b})$ are reported the data obtained with $\mathrm{T}=18.8 \%$ in QCW and CW.

Regarding the beam quality structure, in the near field the laser beam has about a Gaussian intensity distribution. The beam quality factor $\mathrm{M}^{2}$ was measured by means of a CCD camera (model 
BC106, Thorlabs Inc., Newton, NJ, USA) and a beam analysis software, using the output coupler with transmittance $18.8 \%$ (that provided the highest output power both in QCW and in CW pumping conditions). The measurement was carried out at $3.3 \mathrm{~W}$ of output power (i.e., about half of the maximum output power) and it resulted in $\mathrm{M}^{2}{ }_{\mathrm{x}}=2.2, \mathrm{M}_{\mathrm{y}}^{2}=2.4$ in QCW and $\mathrm{M}^{2}{ }_{\mathrm{x}}=2.5, \mathrm{M}_{\mathrm{y}}^{2}=2.8$ in CW pumping conditions (here, $x$ and $y$ refer to the directions respectively parallel and perpendicular to the cavity folding plane, see Figure 4). The far-field intensity distribution both in QCW and in CW pumping mode is shown in Figure 7 . The beam has then a multimode structure, because the pump beam in the sample (radius at $1 / \mathrm{e}^{2} 95 \mu \mathrm{m}$, see above) is larger than the cavity $\mathrm{TEM}_{00}$ mode radius (about $48 \mu \mathrm{m}$ ) in the pumped volume. The asymmetry between the $x$ and the $y$ direction is due to the slight cavity astigmatism introduced by the tilted spherical mirror (i.e., the Folding Mirror FM, see Figure 4). In any case, it must be noticed that no attempt was carried out to optimize the beam quality, but only the power extraction.
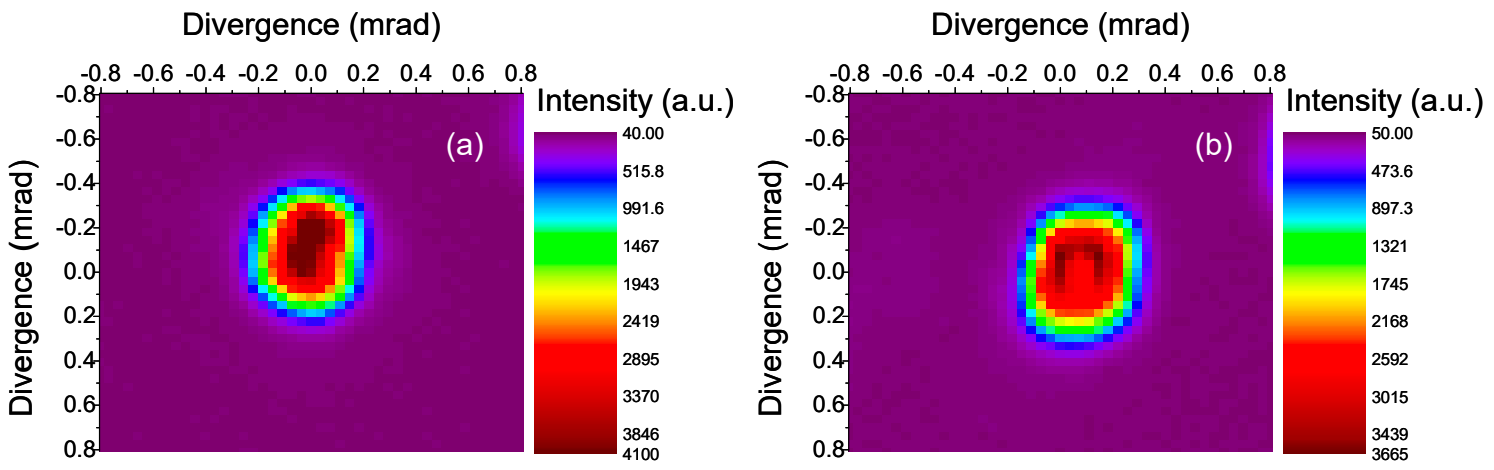

Figure 7. Far-field intensity distribution of the laser beam in QCW (a) and CW (b) pumping conditions.

The tunability range of the ceramic was explored by inserting a ZnSe prism in Brewster configuration (apex angle $41.8^{\circ}$ ) between the FM and the OC. The emission wavelength was measured by a spectrometer with a focal length of $60 \mathrm{~cm}$ equipped with a multichannel detector. The spectral resolution was $0.4 \mathrm{~nm}$. We have measured the output power at several wavelengths (see Figure 8), obtaining a tuning range as wide as $81.5 \mathrm{~nm}$ (i.e., from $\lambda_{\mathrm{L}}=991.5 \mathrm{~nm}$ to $\lambda_{\mathrm{L}}=1073 \mathrm{~nm}$ ). The curve shows two main peaks at $\lambda_{\mathrm{L}}=1030 \mathrm{~nm}$ and $\lambda_{\mathrm{L}}=1050 \mathrm{~nm}$ with an output power of $118 \mathrm{~mW}$ and $89 \mathrm{~mW}$, respectively. The laser emission line width is about $2.5 \mathrm{~nm}$ across the whole tuning range. It is worth noting that the tuning limit at short wavelengths is also affected by the cutoff of the transmission curve of the End Mirror EM (see Figure 4).

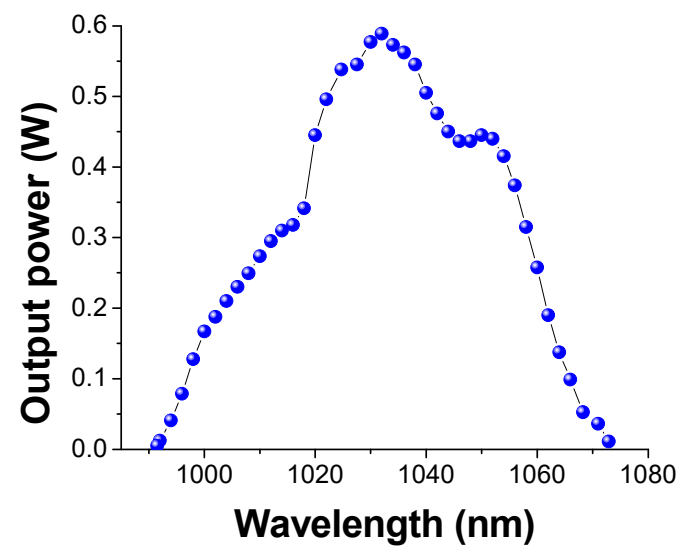

Figure 8. QCW tuning curve. The injected pump power was $19.2 \mathrm{~W}$ corresponding to $\mathrm{P}_{\mathrm{abs}}=11.7 \mathrm{~W}$. 


\section{Conclusions}

In this experiment, we have investigated the microstructural and spectroscopic properties as well as the laser performance of a 10 at. $\%$ Yb:YSAG ceramic fabricated by reactive vacuum sintering. Concerning the spectroscopic characterization, we have determined the absorption and emission cross sections and the lifetime of the upper state of the laser transition. The mixed composition has shown a significant broadening of the main peak of the emission spectrum near $1031 \mathrm{~nm}$ with respect to YAG (13 nm vs. $8.5 \mathrm{~nm}$, FWHM). By comparing our results with previous literature on Yb:YSAG [7,9], it appears that the general trend is toward a broadening of the emission spectrum for increasing content of $\mathrm{Sc}^{3+}$, as discussed above. The upper level lifetime resulted slightly longer than that reported for Yb:YAG, but shorter than those reported for the ceramics with composition $\mathrm{Yb}: \mathrm{Y}_{3} \mathrm{ScAl}_{4} \mathrm{O}_{12}$ (Saikawa et al. [11]) and for the crystal with composition $\mathrm{Yb}: \mathrm{Y}_{3} \mathrm{Sc}_{2} \mathrm{Al}_{3} \mathrm{O}_{12}$ (Dong et al. [9]). The discrepancies in the upper level lifetime could be due to the use of different assessment methodologies, as pointed out above.

Good results are achieved in terms of laser performance such as output power, slope efficiency and laser threshold. A direct comparison can be made with the $\mathrm{CW}$ emission results reported by Saikawa et al. $[7,11]$. The authors obtained a maximum slope efficiency $\eta_{\mathrm{s}}$ of $72 \%$ (maximum output power $\sim 0.6 \mathrm{~W}$ ) under pumping at $970 \mathrm{~nm}$ and a maximum $\eta_{\mathrm{s}}$ of $54 \%$ (max. output power $\sim 0.8 \mathrm{~W}$ ) pumping at $940 \mathrm{~nm}$, using a CW Ti:Sapphire laser as a pump source. The values of the slope efficiencies here reported (up to $67.7 \%$ ) are comparable with the previous results, but the output power levels reached in our experiments are much higher than those previously reported in $[5,7,11]$. It is important to emphasize that our experiments have been carried out using a high power diode laser as a pump source, which is less favorable in terms of beam quality with respect to the Ti:Sapphire laser used in $[7,11]$, but much more relevant in view of practical applications. Finally, the observed tuning range (from $\lambda_{\mathrm{L}}=991.5 \mathrm{~nm}$ to $\lambda_{\mathrm{L}}=1073 \mathrm{~nm}$ ) is much broader than previously reported (from about $1015 \mathrm{~nm}$ to $1065 \mathrm{~nm}$ ) [7].

The results reported here demonstrate a significant advancement in the quality of Yb:YSAG ceramics as a laser gain material. The improvement in the laser performance, indeed, is favored by the high optical and spectroscopic quality of the sample. Further investigations will address the comparison of the spectroscopic and laser performances of Yb:YSAG ceramics with different Sc/Al balance, in order to obtain additional improvements.

Author Contributions: The group at SICCAS (J.L., Y.F., T.X. and Z.Y.) prepared the ceramic samples and took care of the microscopic and crystallographic characterization. The group at IFAC (A.P.) and at INO (G.T., B.P. and M.V.) carried out the spectroscopic characterization and the laser experiments, as well as the preparation of the manuscript. All these Authors contributed equally to this part of the work.

Funding: This activity was partially supported by the CNR Short Term Mobility Program 2017 (Prot. No. 0071950/2017), the National Natural Science Foundation of China (Grant No. 61575212), the Key research project of the frontier science of the Chinese Academy of Sciences (No. QYZDB-SSW-JSC022) and the National Key R\&D Program of China (Grant No. 2017YFB0310500).

Conflicts of Interest: The authors declare no conflict of interest.

\section{References}

1. Pirri, A.; Toci, G.; Li, J.; Xie, T.; Pan, Y.; Babin, V.; Beitlerova, A.; Nikl, M.; Vannini, M. High efficiency laser action in mildly doped Yb:LuYAG ceramics. Opt. Mater. 2016, 73, 312-318. [CrossRef]

2. Pirri, A.; Toci, G.; Li, J.; Xie, T.; Pan, Y.; Babin, V.; Beitlerova, A.; Nikl, M.; Vannini, M. Spectroscopic and laser characterization of $\mathrm{Yb}_{0.15}$ : $\left(\mathrm{Lu}_{\mathrm{x}} \mathrm{Y}_{1-\mathrm{x}}\right)_{3} \mathrm{Al}_{5} \mathrm{O}_{12}$ ceramics with different $\mathrm{Lu} / \mathrm{Y}$ balance. Opt. Express 2016, 24, 17832-17842. [CrossRef] [PubMed]

3. Toci, G.; Pirri, A.; Li, J.; Xie, T.; Pan, Y.; Babin, V.; Beitlerova, A.; Nikl, M.; Vannini, M. First laser emission of $\mathrm{Yb}_{0.15}:\left(\mathrm{Lu}_{0.5} \mathrm{Y}_{0.5}\right)_{3} \mathrm{Al}_{5} \mathrm{O}_{12}$ ceramics. Opt. Express 2016, 24, 9611-9616. [CrossRef] [PubMed] 
4. Walsh, B.M.; Barnes, N.P.; Hutcheson, R.L.; Equal, R.W. Compositionally tuned 0.94- $\mu$ m lasers: A comparative laser material study and demonstration of 100-mJ Q-switched lasing at 0.946 and $0.9441 \mu \mathrm{m}$. IEEE J. Quantum Electron. 2001, 37, 1203-1209. [CrossRef]

5. Saikawa, J.; Sato, Y.; Taira, T.; Ikesue, A. Passive mode locking of a mixed garnet $\mathrm{Yb}: \mathrm{Y}_{3} \mathrm{ScAl}_{4} \mathrm{O}_{12}$ ceramic laser. Appl. Phys. Lett. 2004, 85, 5845-5847. [CrossRef]

6. Kück, S.; Petermann, K.; Pohlmann, U.; Schönhoff, U.; Huber, G. Tunable room-temperature laser action of $\mathrm{Cr}^{4+}$-doped $\mathrm{Y}_{3} \mathrm{Sc}_{\mathrm{x}} \mathrm{Al}_{5-\mathrm{x}} \mathrm{O}_{12}$. Appl. Phys. 1994, 58, 153-156. [CrossRef]

7. Saikawa, J.; Sato, Y.; Taira, T.; Ikesue, A. Femtosecond $\mathrm{Yb}^{3+}$-doped $\mathrm{Y}_{3}\left(\mathrm{Sc}_{0.5} \mathrm{Al}_{0.5}\right)_{5} \mathrm{O}_{12}$ ceramic laser. Opt. Mater. 2007, 29, 1283-1288. [CrossRef]

8. Südmeyer, T.; Kränkel, C.; Baer, C.R.E.; Heckl, O.H.; Saraceno, C.J.; Golling, M.; Peters, R.; Petermann, K.; Huber, G.; Keller, U. High-power ultrafast thin disk laser oscillators and their potential for sub-100-femtosecond pulse generation. Appl. Phys. B 2009, 97, 281-295. [CrossRef]

9. Dong, J.; Ueda, K.; Kaminskii, A.A. Continuous-wave and Q-switched microchip laser performance of $\mathrm{Yb}: \mathrm{Y}_{3} \mathrm{Sc}_{2} \mathrm{Al}_{3} \mathrm{O}_{12}$ crystals. Opt. Express 2008, 16, 5241-5251. [CrossRef] [PubMed]

10. Allik, T.H.; Morrison, C.A.; Gruber, J.B.; Kokta, M.R. Crystallography, spectroscopic analysis, and lasing properties of $\mathrm{Nd}^{3+}: \mathrm{Y}_{3} \mathrm{Sc}_{2} \mathrm{Al}_{3} \mathrm{O}_{12}$. Phys. Rev. B 1990, 41, 21-30. [CrossRef]

11. Saikawa, J.; Sato, Y.; Taira, T.; Ikesue, A. Absorption, emission spectrum properties, and efficient laser performances of $\mathrm{Yb}: \mathrm{Y}_{3} \mathrm{Sc}_{2} \mathrm{Al}_{3} \mathrm{O}_{12}$ ceramics. Appl. Phys. Lett. 2004, 85, 1898-1900. [CrossRef]

12. Bensalah, A.; Guyot, Y.; Ito, M.; Brenier, A.; Sato, H.; Fukuda, T.; Boulon, G. Growth of $\mathrm{Yb}^{3+}-\mathrm{doped}_{\mathrm{YLiF}}$ laser crystal by the Czochralski method. Attempt of $\mathrm{Yb}^{3+}$ energy level assignment and estimation of the laser potentiality. Opt. Mater. 2004, 26, 375-383. [CrossRef]

13. Antic-Fidancev, E. Simple way to test the validity of ${ }^{2 \mathrm{~S}+1} \mathrm{~L}_{\mathrm{J}}$ barycenters of rare earth ions (e.g., $4 \mathrm{f}^{2}, 4 \mathrm{f}^{3}$ and $4 \mathrm{f}^{6}$ configurations). J. Alloy. Compd. 2000, 300-301, 2-10. [CrossRef]

14. Sato, Y.; Taira, T.; Ikesue, A. Spectral Parameters of $\mathrm{Nd}^{3+}$-ion in the Polycrystalline Solid-Solution Composed of $\mathrm{Y}_{3} \mathrm{Al}_{5} \mathrm{O}_{12}$ and $\mathrm{Y}_{3} \mathrm{Sc}_{2} \mathrm{Al}_{3} \mathrm{O}_{12}$. Jpn. J. Appl. Phys. 2003, 42, 5071-5074. [CrossRef]

15. Ma, J.; Wang, J.; Shen, D.; Ikesue, A.; Tang, D. Generation of sub-100-fs pulses from a diode-pumped $\mathrm{Yb}: \mathrm{Y}_{3} \mathrm{ScAl}_{4} \mathrm{O}_{12}$ ceramic laser. Chin. Opt. Lett. 2017, 15, 121403.

16. Galzerano, G.; Laporta, P.; Sani, E.; Bonelli, L.; Toncelli, A.; Tonelli, M.; Pesatori, A.; Svelto, C. Room-temperature diode-pumped $\mathrm{Yb}: \mathrm{KYF}_{4}$ laser. Opt. Lett. 2006, 31, 3291-3293. [CrossRef] [PubMed]

17. Alderighi, D.; Pirri, A.; Toci, G.; Vannini, M. Tunability enhancement of Yb:YLF based laser. Opt. Express 2010, 18, 2236-2241. [CrossRef] [PubMed]

18. Pirri, A.; Alderighi, D.; Toci, G.; Vannini, M.; Nikl, M.; Sato, H. Direct Comparison of $\mathrm{Yb}^{3+}: \mathrm{CaF}_{2}$ and heavily doped $\mathrm{Yb}^{3+}:$ YLF as laser media at room temperature. Opt. Express 2009, 17, 18312-18319. [CrossRef] [PubMed]

19. Xu, X.; Zhao, Z.; Xu, J.; Deng, P. Distribution of ytterbium in Yb:YAG crystals and lattice parameters of the crystals. J. Cryst. Growth 2003, 255, 338-341. [CrossRef]

20. DeLoach, L.D.; Payne, S.A.; Chase, L.L.; Smith, L.K.; Kway, W.L.; Krupke, W.F. Evaluation of absorption and emission properties of $\mathrm{Yb}^{3+}$ doped crystals for laser applications. IEEE J. Quantum Electron. 1993, 29, 1179-1191. [CrossRef]

21. Toci, G. Lifetime measurements with the pinhole method in presence of radiation trapping: I-Theoretical model. Appl. Phys. B 2012, 106, 63-71. [CrossRef]

22. Toci, G.; Alderighi, D.; Pirri, A.; Vannini, M. Lifetime measurements with the pinhole method in presence of radiation trapping: II-Application to $\mathrm{Yb}^{3+}$ doped ceramics and crystals. Appl. Phys. B 2012, 106, 73-79. [CrossRef]

23. Kühn, H.; Fredrich-Thornton, S.T.; Kränkel, C.; Peters, R.; Petermann, K. Model for the calculation of radiation trapping and description of the pinhole method. Opt. Lett. 2007, 32, 1908-1910. [CrossRef] [PubMed]

24. Caird, A.; Payne, S.A.; Staber, P.R.; Ramponi, A.J.; Chase, L.L.; Krupke, W.F. Quantum electronic properties of the $\mathrm{Na}_{3} \mathrm{Ga}_{2} \mathrm{Li}_{3} \mathrm{~F}_{12}: \mathrm{Cr}^{3+}$ laser. IEEE J. Quantum Electron. 1988, 24, 1077-1099. [CrossRef]

(C) 2018 by the authors. Licensee MDPI, Basel, Switzerland. This article is an open access article distributed under the terms and conditions of the Creative Commons Attribution (CC BY) license (http:/ / creativecommons.org/licenses/by/4.0/). 